\title{
Influence of turbulence and in-stream structures on the transport and survival of grass carp eggs and larvae at various developmental stages
}

\author{
Andres F. Prada ${ }^{1}$ D $\cdot$ Amy E. George ${ }^{2}$ D $\cdot$ Benjamin H. Stahlschmidt ${ }^{2} \cdot$ Patrick Ryan Jackson $^{3} \cdot$ Duane C. Chapman $^{2}$. \\ Rafael O. Tinoco ${ }^{1}$
}

Received: 15 May 2019 / Accepted: 10 December 2019 / Published online: 18 December 2019

(c) The Author(s) 2019

\begin{abstract}
Understanding the response of grass carp to flow and turbulence regimes during early life stages is fundamental to monitoring and controlling their spread. A comprehensive set of hydrodynamic experiments was conducted with live grass carp eggs and larvae, to better understand their drifting and swimming patterns with 3 different in-stream obstructions: (1) a gravel bump, (2) a single cylinder, and (3) submerged vegetation. The hydrodynamic behavior of eggs and larvae with each obstruction was continuously monitored for about 85 consecutive hours. Transient spatial distributions of the locations of eggs and larvae throughout the water column were generated for each flow scenario. Results show that the active swimming capabilities of larvae allow them to seek areas of low turbulence and low shear stresses, and that eggs are susceptible to damage by high levels of turbulence, which was further corroborated with tests in an oscillating grid-stirred turbulence tank. Our study seeks to better inform field collection of grass carp during early life stages, and to guide the design of alternative approaches to control the dispersal of this invasive species in North America.
\end{abstract}

Keywords Grass carp · Transport of eggs and larvae $\cdot$ Swimming behavior $\cdot$ Turbulence $\cdot$ Mortality

Rafael O. Tinoco

tinoco@illinois.edu

Andres F. Prada

pradase2@illinois.edu

Amy E. George

ageorge@usgs.gov

Benjamin H. Stahlschmidt

bstahlschmidt@usgs.gov

Patrick Ryan Jackson

pjackson@usgs.gov

Duane C. Chapman

dchapman@usgs.gov

1 Department of Civil and Environmental Engineering, University of Illinois At Urbana-Champaign, $205 \mathrm{~N}$ Mathews Ave. M/C 250, Urbana, IL 61801, USA

2 U.S. Geological Survey, Columbia Environmental Research Center, Columbia, MO, USA

3 U.S. Geological Survey, Central Midwest Water Science Center, Urbana, IL, USA

\section{Introduction}

After being introduced in the United States in the 1970s for private aquaculture, grass carp (Ctenopharyngodon idella) and their relatives, the bigheaded carps (silver carp Hypophthalmichthys molitrix and bighead carp H. nobilis) moved into the Mississippi River basin where they became well established and are now considered highly undesirable invaders (Chick and Pegg 2001; Parker et al. 2016; Kočovský et al. 2018). These species are of particular ecological concern for their rapid population growth and their high consumption capacity (Conover et al. 2007). Specifically, grass carp can consume up to $40 \%$ of their body weight per day in aquatic vegetation (Laird and Page 1996). Reduction in aquatic vegetation may result in increases in turbidity and alkalinity, and depletion of dissolved oxygen (Lembi et al. 1978; Mitzner 1978; Leslie et al. 1983), as well as direct degradation of habitat of native fish species which depend upon macrophytes for all or part of their life cycle (Chilton and Muoneke 1992; Cudmore et al. 2012). Conversely, grass carp are a highly desirable species in their native rivers, where their populations have declined due in 
part to anthropogenic river modifications (Chapman et al. 2016).

Grass carp eggs need to be in suspension in the water column in order to achieve high hatch rates (Conover et al. 2007; George et al. 2015), which requires continuously flowing, turbulent flows to avoid settling. Increases in discharge are often correlated with spawning events, and studies in the Yangtze River also indicated a positive correlation between spawning activity and vorticity (for vorticity values in the order of $0.5 \mathrm{~s}^{-1}$, Liu et al. 2018). However, temperature (between 15 and $30^{\circ} \mathrm{C}$ ) seems to be a primary driver of spawning behavior for grass carp and bigheaded carps (Schrank and Guy 2002; Coulter et al. 2016). Spawning of grass carp is proportional to the size and weight of the female, with an average spawn of 500,000 eggs for a $5 \mathrm{~kg}$ female (Shireman and Smith 1983; Chilton and Muoneke 1992). Eggs disperse in flow, from the spawning site to as far as $180 \mathrm{~km}$ downstream (Fedorenko and Fraiser 1978), although dispersal distance of eggs can also be relatively short depending on temperature and flow conditions (Garcia et al. 2015; Embke et al. 2019). After hatching, larvae begin vertical swimming, which continues until gas bladder inflation (GBI), and the onset of horizontal swimming, when larvae can maintain depth and position within still water (George and Chapman 2015). In natural fluvial systems, larvae then begin to move from mainstem rivers into tributaries, backwaters, and other low velocity nursery habitats. At this point, larval grass carp must have enough swimming capacity to navigate through or avoid regions of higher turbulence, shear, and vorticity, where their natural undulating swimming style may be disturbed, and where larvae must spend more energy to maintain their position.

A strategy to prevent the spread of invasive carps, and reduce their population growth, is to identify survival and dispersal bottlenecks due to physical interactions between the early life stages and the riverine environment. George et al. (2015) showed a reduction in survival when eggs are buried by sediment, thus a balance between levels of turbulence sufficient to keep the egg suspended, but low enough to not damage eggs is necessary for survival. Understanding the response of grass carp to flow and turbulence during early life stages is fundamental to monitoring and controlling their spread. In natural fluvial systems, regions of high mixing levels (e.g. river confluences, rapids, behind sandbars, over vegetation canopies and gravel beds) are often used as spawning grounds (Jennings 1988; Chapman 2006; Stainbrook et al. 2007; Garcia et al. 2013), thus it is important to understand how mean and turbulent flow properties due to complex bed morphologies affect larval survival, dispersal, and behavior.

Prada et al. (2018) conducted laboratory experiments in moving water with live grass carp eggs and larvae in developmental stages 8-38 (blastula to GBI; based on stages described by Yi et al. 1988 and George and Chapman 2015), to quantify survival rates and observe drifting and swimming behavior under different flow conditions over a flat sediment bed. They showed vertical distributions of eggs and larvae within the water column over time. Eggs drifted mostly below the top quarter of the water column, with a slight tendency to be found more concentrated towards the bottom. Larvae were able to choose the regions with lower turbulence levels, e.g. far from the bed, as swimming capabilities developed. This initial investigation provides support for field campaigns, e.g. Embke et al. (2016) where researchers had difficulty collecting even a few grass carp eggs using ichthyoplankton nets deployed, near the water surface during high-flow events on the Sandusky River in Ohio. Prada et al. (2018) recommended sampling deeper in the water column, to increase the probability of successful capture for future field collections, especially at lower water velocity and turbulence. However, this recommendation was made based on results over a flat bed, without the presence of in-stream obstructions typical of natural streams. More extensive analysis of experimental live-fish laboratory data is needed to identify more precisely where grass carp eggs and larvae are more likely to be found in rivers with complex river bed morphologies.

In this study, laboratory flume experiments were conducted to determine the drifting and swimming behaviors of live grass carp eggs and larvae with a constant flow velocity and three different in-stream obstructions: a gravel bump, a single cylinder, and submerged vegetation. Eggs and larvae were monitored continuously over $\sim 85 \mathrm{~h}$ as they drifted and swam and mortality rates were estimated in each scenario. Our objective was to compare the flow conditions generated by each bed morphology (streamwise flow velocity, turbulence, and vorticity) with commonly used locations of eggs and larvae across water depth, to improve the likelihood of detection during field collection. We also examined enhanced flow turbulence as an alternative control strategy through turbulence-induced mortality at hatching transition.

\section{Materials and methods}

Three trials of experiments were conducted in a RaceTrack Flume (RTF, Fig. 1), an Odell-Kovasznay type flume (Odell and Kovasznay 1971), located at the Ven Te Chow Hydrosystems Laboratory (VTCHL) at the University of Illinois at Urbana-Champaign. The 6.0-m RTF has a 2.0-m long and $0.15-\mathrm{m}$ wide test section where all measurements were taken (Fig. 1a). Temperatures in the flume were maintained at $23-24{ }^{\circ} \mathrm{C}$ using a submerged aquarium heater.

The Illinois Department of Natural Resources granted us the authorization to possess diploid grass carp (Ctenopharyngodon idella) eggs and larvae in the laboratory facility 
Fig. 1 Schematic view of the Race-Track Flume (RTF) (a), and side view of the studied in-stream obstructions (not to scale): gravel bump in trial 1 (b), single cylinder in trial 2 (c), and submerged vegetation in trial 3 (d)
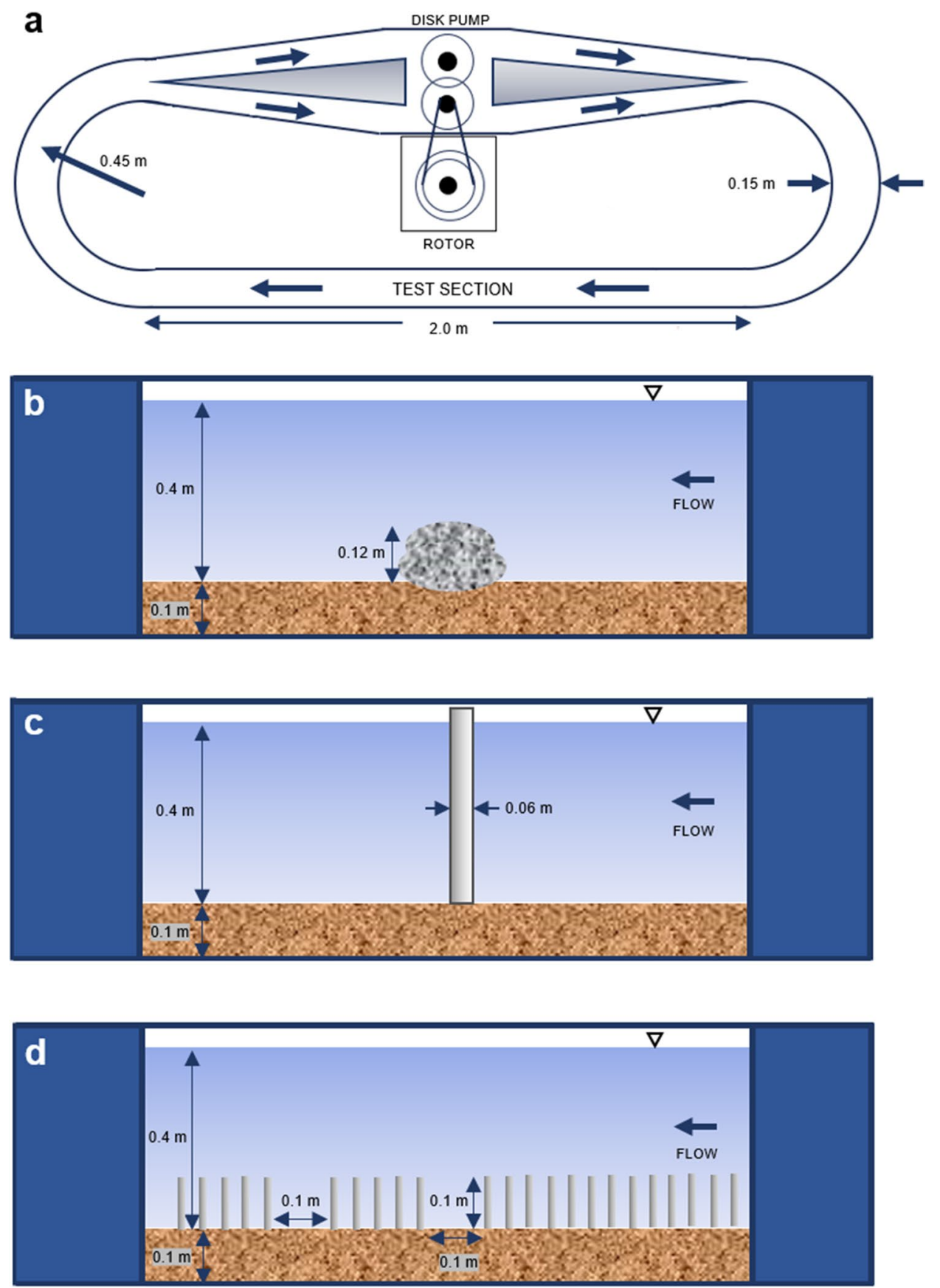

for research purposes only (Permit No. 18-050). Grass carp were spawned by hormone induction and eggs were fertilized at the U.S. Geological Survey Columbia Environmental Research Center (CERC) in Columbia, MO. Fish were obtained from earthen ponds located at CERC. For trial 1, eggs were collected for fertilization from two female grass carp, both weighing $7.2 \mathrm{~kg}$, and high-quality milt was collected from three male grass carp weighing 3.2, 3.2, and $2.0 \mathrm{~kg}$. For trial 2, eggs were collected from one female grass carp, weighing $6.9 \mathrm{~kg}$, and high-quality milt was collected from three male grass carp, weighing 2.5, 3.3 and
$4.7 \mathrm{~kg}$. For trial 3, eggs were collected from one female grass carp, weighing $2.6 \mathrm{~kg}$, and milt was collected from two male grass carp, weighing 3.1 and $4.1 \mathrm{~kg}$. Milt quality for the third spawning event was graded highly, but egg quality for this female was poor, as atresia had started. High fertilization rates were not expected. In each trial, eggs were stripped into a bowl and fertilized with the combined milt from all males by the dry method (Piper et al. 1982), for $1 \mathrm{~min}$. Once fertilized, eggs were then rinsed and placed into a water bath for $30 \mathrm{~min}$ to allow water-hardening. Diameter from a subsample of 100 eggs was measured, using a Nikon 
SMZ-1500 stereomicroscope and NIS Elements software, as the mean of two perpendicular measurements, with a tolerance of $0.01 \mathrm{~mm}$. Eggs were then stocked into polyethylene transport bags containing well water. Pure oxygen was used to fill the space above the water inside of the bags in order to keep the dissolved oxygen levels of the water from dropping during transport. The plastic bags were sealed and place into coolers for 4.5-hours transport to the VTCHL.

For all trials, 4000 eggs were released in the RTF, where water depth was maintained at $H=0.4 \mathrm{~m}$ above a $0.1-\mathrm{m}$ thick sediment bed composed of a mixture of walnut shells and sand (bulk sediment density $\rho_{p}=1250 \mathrm{~kg} \mathrm{~m}^{-3}$, settling velocity $w_{p}=1.89 \times 10^{-2} \mathrm{~m} \mathrm{~s}^{-1}$, and size $\{\mathrm{D} 16, \mathrm{D} 50$, $\mathrm{D} 84\}=\{0.41,0.54,0.66\} \mathrm{mm})$ (Prada et al. 2018). All substrate material was washed and dried in an oven at $170 \mathrm{~F}$ $\left(77^{\circ} \mathrm{C}\right.$ ) for $48 \mathrm{~h}$ before each trial to help prevent biological contamination and control the spread of fungus. Flow in the RTF is driven by a vertical-axis disk pump, controlled by a frequency inverter. Frequency was set at $f=20 \mathrm{~Hz}$ for all trials. The relationship between the inverter frequency and the rotation speed of the disk pump is given by $\Omega$ [RPM] $=6.6$ $f[\mathrm{~Hz}]$, so a frequency of $20 \mathrm{~Hz}$ corresponds to a disk rotation rate of 132 RPM, and an approximate mean velocity of $0.15 \mathrm{~m} \mathrm{~s}^{-1}$ over the flat bed in the straight section of width-to-depth ratio of $3 / 8$. The side walls may add no-slip boundaries that create viscous sublayers where flow velocity is reduced to zero and shear stresses increase. However, as reported by Prada et al. (2018), these boundary layers can be very thin, and may not affect the mean flow or the egg and larva distribution across the water depth.

Altered flows were created over the straight test section by 3 different in-stream obstructions, maintaining the same water depth $(0.4 \mathrm{~m})$ and forcing $(f=20 \mathrm{~Hz}$-rotational frequency of the disk pump), to keep a constant bulk (cross sectional averaged) discharge. In trial 1, a 0.12-m high gravel bump, composed of gravel (mean size of $350 \mathrm{~mm}$ ) contained in a mesh bag, was placed in the middle of the test section (Fig. 1b). For trial 2, an emergent 2" (51 mm) diameter-PVC cylinder was embedded in the middle of the test section (Fig. 1c), allowing for $49 \mathrm{~mm}$ of space between the cylinder and the walls of the flume. For trial 3, patches of submerged rigid acrylic rods $(6.4 \mathrm{~mm}$ diameter and $100 \mathrm{~mm}$ in height), mimicking submerged vegetation, were placed in the sediment throughout the test section (Fig. 1d). The rigid vegetation followed a staggered configuration with average spacing between rods of $0.034 \mathrm{~m}$, porosity of $6.3 \times 10^{-3}$, and volumetric frontal area $1.27\left(\mathrm{~m}^{-1}\right)$.

Results from Prada et al. (2018) did not separate the effect of turbulence, shear, egg-sediment interactions, and potential collisions with the disk-pump or flume walls, on the mortality rates during those trials. To examine the effects of pure turbulence, we included a test in a $0.5 \mathrm{~m} \times 0.5 \mathrm{~m} \times 0.5 \mathrm{~m}$ oscillating grid-stirred turbulence tank (Fig. 2), with oscillations driven by a motor controlled by a frequency inverter. The grid is composed of bars with squared section of $0.012 \mathrm{~m}$ in width, and spacing of $0.05 \mathrm{~m}$. Videos from each test reveal that the eggs that get closer to the grid pass within the grid openings pushed by the flow, rather than being impacted by the grid itself.

\section{Flow characterization}

Flow fields were characterized, in both the RTF and the turbulence tank, using a 2D Particle Image Velocimetry (PIV)
Fig. 2 Oscillating grid-stirred turbulence tank and its dimensions
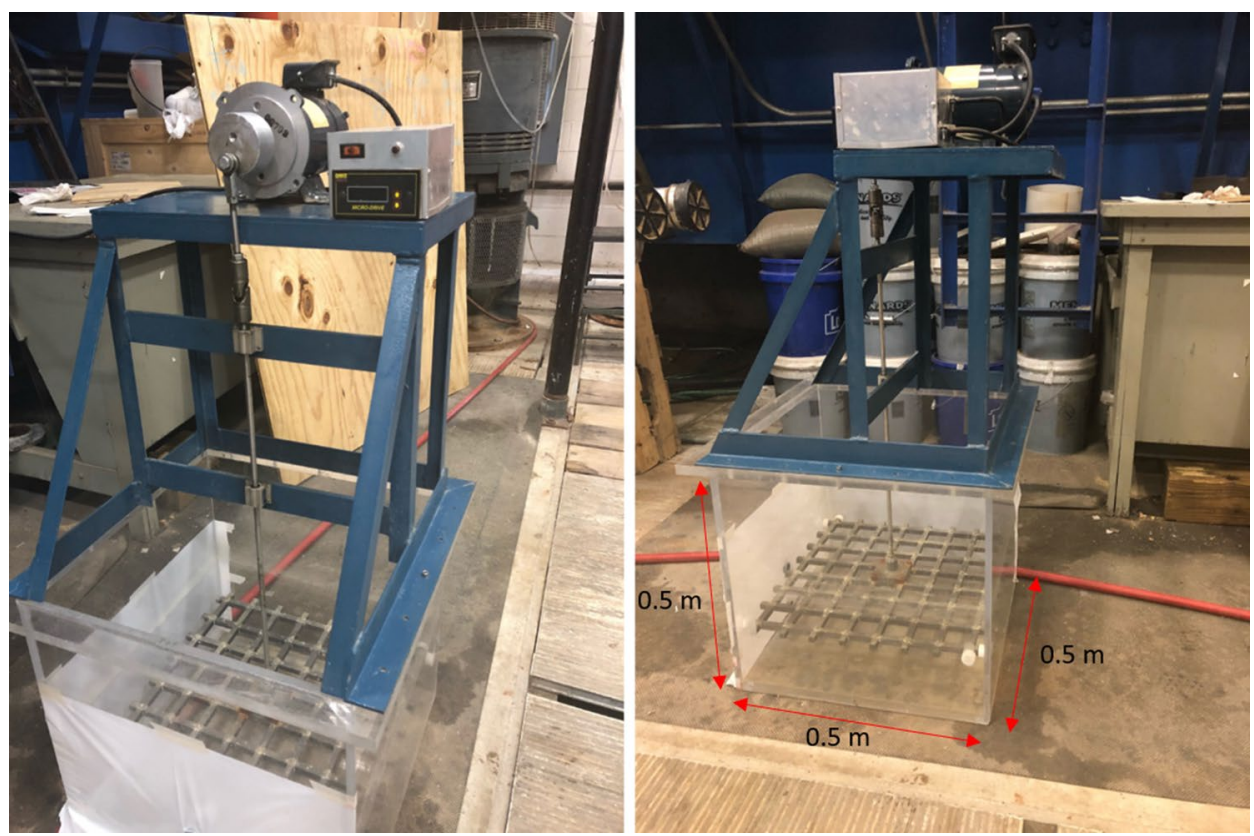
system, with a 60fps 5MP monochromatic camera and a $5 \mathrm{~W}$ Continuous-Wave $532 \mathrm{~nm}$ Laser. A vertical laser sheet was generated to illuminate neutrally buoyant silver-coated hollow glass spheres with a mean diameter of $10 \mu \mathrm{m}$.

In all trials, the camera was placed laterally at $0.8 \mathrm{~m}$ from the flume's test section and the laser sheet was generated from top, parallel to the mean flow at the in-stream obstruction. However, for trial 3 (simulated vegetation), a small gap of $0.1 \mathrm{~m}$ was set in the middle of the section to take the PIV measurements (Fig. 1d). In the turbulence tank, the laser sheet was generated perpendicular to the grid, entering from one side of the tank at the middle of its cross section to create a vertical light sheet. All PIV measurements were collected after the three trials of live-fish experiments, to avoid: (a) dissolved microspheres affecting egg or larval health, and (b) altering larval behavior due to the laser sheet.

Images were processed using the GUI-based open-source tool PIVlab in MATLAB ${ }^{\circledR}$ (Thielicke and Stamhuis 2014). Pairs of consecutive frames were cross-correlated to estimate the most probable particle displacement in small interrogation windows. The correlation matrix was computed by applying a discrete Fourier transform (Soria 1996), and a spline window deformation was used as interpolator. This cross correlation provided us with instantaneous velocity fields $\vec{u}(x, z)_{i}=\left(u_{x}(x, z), u_{z}(x, z)\right)_{i}$ across the illuminated area, where $x$ is the horizontal coordinate increasing downstream from each obstruction and $z$ is the vertical coordinate increasing upwards from the sediment bed.

Instantaneous velocity fields were time averaged to obtain the mean streamwise velocity $\vec{U}(x, z)=\overline{\vec{u}(x, z)_{i}}$. Reynolds decomposition was applied to estimate turbulent fluctuations as $\vec{u}^{\prime}(x, z)_{i}=\vec{u}(x, z)_{i}-\vec{U}(x, z)$, and then compute turbulent kinetic energy $(k)$ and Reynolds stresses $\left(\tau_{x z}\right)$ as

$k(x, z)=0.5\left(2 \overline{u_{x}^{\prime 2}(x, z)}{ }_{i}+\overline{u_{z}^{\prime 2}(x, z)}{ }_{i}\right)$

$\operatorname{assuming} u_{x}^{\prime}=u_{y}^{\prime}$. And

$\tau_{x z}(x, z)=\rho \overline{\left(u_{x}^{\prime}(x, z)_{i} \cdot u_{z}^{\prime}(x, z)_{i}\right)}$

where $\rho$ is the water density. Vorticity was also computed as (with negative vorticity as clockwise rotations):

$\vec{\omega}(x, z)=\vec{\nabla} \times \vec{U}$

\section{Survival rates}

A subset of eggs in each trial was kept in hatching jars with a gentle upwelling current to provide oxygenation and a similar water temperature to the RTF, at $23-24{ }^{\circ} \mathrm{C}$, maintained with a submersible heater and monitored with $\mathrm{HOBO}^{\circledR}$ temperature loggers (Onset Computer Corporation, Cape Cod,
Massachusetts) as a baseline to ascertain survival differences $(\%$ diff $=(\%$ flume $-\%$ jars $) \times 100 / \%$ jars $)$. Each hatching jar housed 500 eggs during trials 1 and 2; but only 100 during trial 3 due to the poor-quality eggs. A 500-gallon tank, refilled as needed with well water from the same source, supplied the water bath and the flume throughout the experiments. On day 5 of each trial, the percentage of surviving larvae in the RTF was computed and compared against the percentage of surviving larvae in the water bath.

Sets of 100 eggs were dropped in the turbulence tank for each test, exposing them to increased levels of turbulence for a period of $1 \mathrm{~min}$, at motor frequencies of 100 , 200, 240,320,360, and $400 \mathrm{~Hz}$. A linear relationship exists between the inverter frequency and the rotation speed of the motor, given by $\Omega[\mathrm{RPM}]=1.07 f[\mathrm{~Hz}]$. Each 1-min test was repeated 3 times, and then eggs were removed from the tank with handheld nets and only those with intact membrane were counted as survivors.

To prevent the escape of eggs or larvae from the facility, MS-222 (tricaine methanesulfonate) was used to euthanize all surviving larvae according to protocol. Remaining organic material was filtered and incinerated.

\section{Eggs and larvae spatial distributions}

Drifting and swimming behavior of eggs and larvae was recorded for $\sim 85$ consecutive hours in each trial with two side-looking cameras, both placed at $0.5 \mathrm{~m}$ from the RTF's test section, one next to each other. LED Edge Lit panels (Knema, LLC) were used to illuminate the test section from behind, creating a uniform illumination field. A Nikon D7100 camera (24.1MP) was used to take time-lapse photos (1 per minute) to generate 1D and 2D plots of transient distributions of eggs and larvae across the water column. For 1D plots, custom MATLAB ${ }^{\circledR}$ scripts were developed to detect the centroids in each photo, store, and count the number of particles within 9 equal intervals ( $0.044 \mathrm{~m}$ each) in the $0.40 \mathrm{~m}$ of water depth.

For 2D plots, a custom MATLAB ${ }^{\circledR}$ script was developed to estimate percentage distributions of eggs and larvae found on 500 images at every developmental period, thus identify in more detail the spots of higher probability for successful sampling downstream of each obstruction.

A Nikon D5300 camera $(1920 \times 1080$ video resolution $)$ was used to record 10 -min videos (30 fps) every $4 \mathrm{~h}$, to observe drifting and swimming pathways of eggs and larvae based on each flow condition and the dependence on developmental stage. Plots of egg and larval trajectories were generated from consecutive frames extracted from the videos, which were processed to take the maximum of pixel intensities from groups of 300 frames. An extra test was conducted with the euthanized larvae on day 5 of each trial. Dead larvae were released back to the flume to record an 
extra 10-min video in each trial to compare their trajectories with live larvae. This test allowed us to determine whether live larvae can actively identify and swim towards specific desired locations within the flow, or if they are just drifting and being captured in recirculation zones as inert particles.

\section{Results}

\section{Flow characterization}

The in-stream obstructions created regions with a large contrast in mean velocity, turbulent kinetic energy, and vorticity. In the case of the gravel bump (trial 1), the resulting map of the streamwise flow velocity (Fig. 3a) shows values ranging from 0 to $0.2 \mathrm{~m} \mathrm{~s}^{-1}$. Flow moved faster, at a magnitude of $0.2 \mathrm{~m} \mathrm{~s}^{-1}$, on top of the gravel bump, and sharply transitioned towards a mean $0 \mathrm{~m} \mathrm{~s}^{-1}$ immediately downstream of the bump. In this sharp transition in the velocity profile there is a region of high $k$ and $\omega$ (Fig. 3b, c). Values of $k_{\max }=1.5 \mathrm{~m}^{2} \mathrm{~s}^{-2}$ and $\omega_{\max }=-8 \times 10^{-3} \mathrm{~s}^{-1}$ were estimated in this region. Trajectories of "inert particles", eggs (Fig. 3d) and dead larvae (Fig. 3f), were almost uniformly distributed throughout the flow. However, live larvae in stage 38 (Fig. 3e), capable of horizontal swimming after GBI, avoided the region of high $k$ and $\omega$, and actively sought low-energy flow regions.

For the single cylinder (trial 2), the flow field maps (Fig. $4 a-c)$ show a reduced streamwise velocity in the wake behind the cylinder, as well as increased $k$ and $\omega$ across
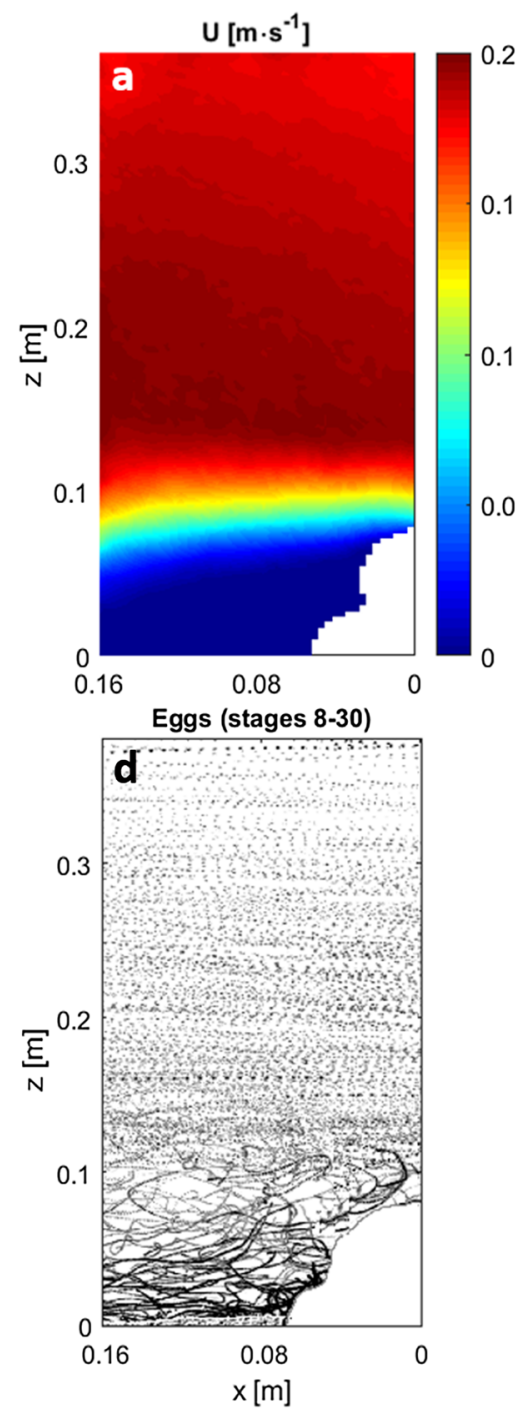

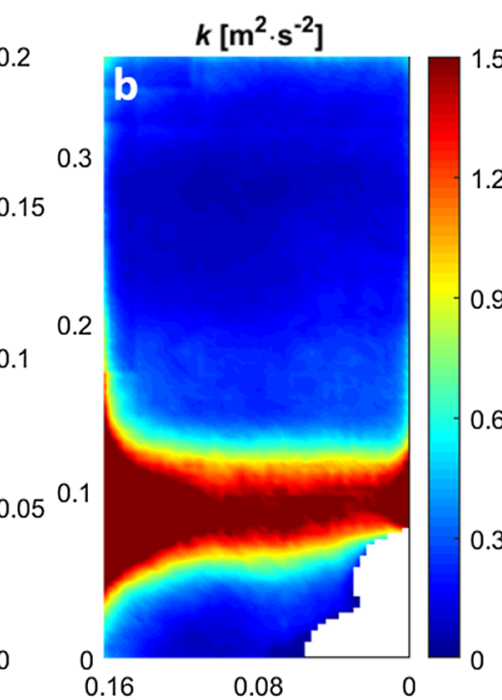

Live larvae (stages $37-38$ )

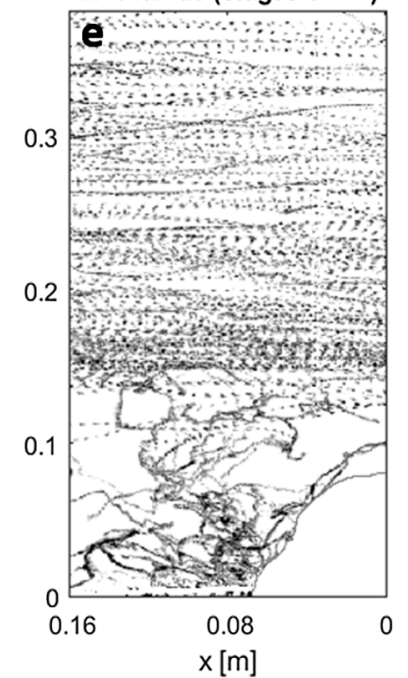

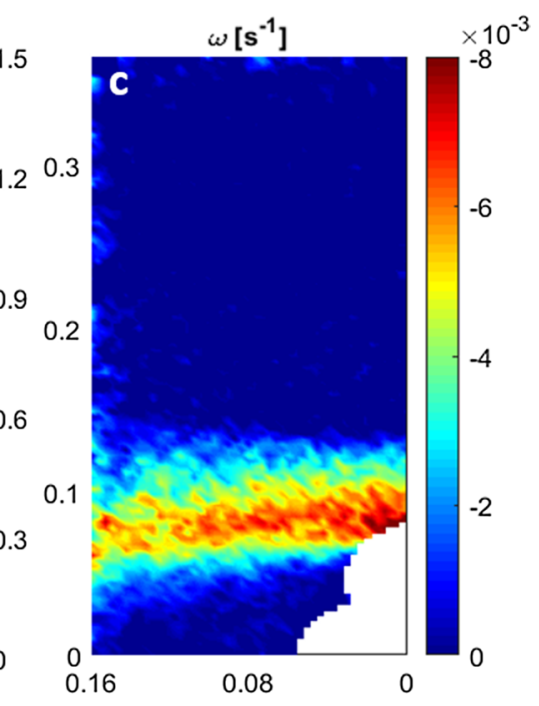

Dead larvae (stage 38)

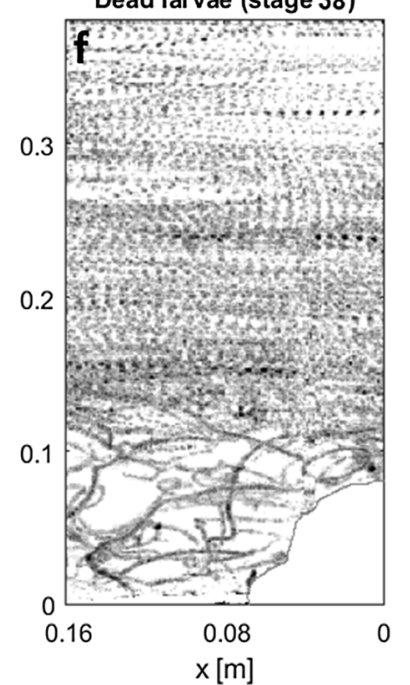

Fig. 3 Maps of flow conditions and trajectories of eggs and larvae under the presence of the gravel bump in the middle of the straight section. a Map of streamwise flow velocity. b Map of turbulent kinetic energy. c Map of vorticity. d Trajectories of eggs. e Trajectories of live larvae in stage 38. $\mathbf{f}$ Trajectories of dead larvae in stage 38 


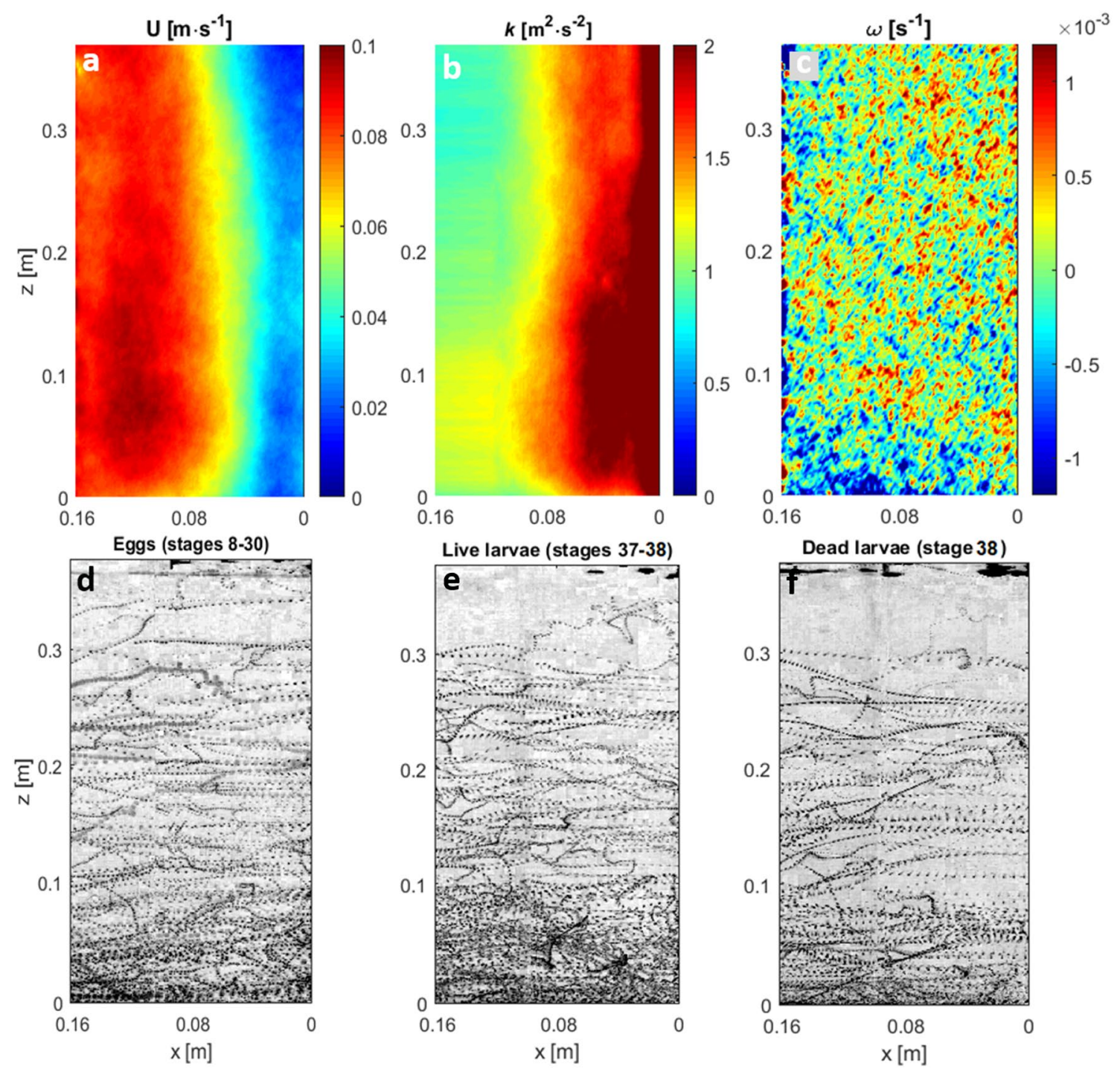

Fig. 4 Maps of flow conditions and trajectories of eggs and larvae under the presence of the single cylinder in the middle of the straight section. a Map of streamwise flow velocity. b Map of turbulent

the water depth. Figure 4a shows the velocity recovery as water moves past the cylinder, going from near $0 \mathrm{~m} \mathrm{~s}^{-1}$ mean speed to around $0.1 \mathrm{~m} \mathrm{~s}^{-1}$. Figure $4 \mathrm{~b}$ shows the spatial evolution of turbulence along the wake, with $k_{\max }=2.0$ $\mathrm{m}^{2} \mathrm{~s}^{-2}$. Figure $4 \mathrm{c}$ shows a range of vorticity between $-1 \times 10^{-3}<\omega<1 \times 10^{-3} \mathrm{~s}^{-1}$, as opposing eddies were distributed throughout the test region.

Trajectories of eggs and larvae (live and dead) at the same location (Fig. 4d-f) show that although high levels of $k$ and $\omega$ are almost evenly distributed across the water depth, there are fewer larvae (both dead and alive) near the free surface within the wake of the cylinder. There is also a larger accumulation of larvae than eggs near the bed, with a tendency of live larvae to be found in that area; in contrast to dead kinetic energy. c Map of vorticity. d Trajectories of eggs. e Trajectories of live larvae in stage 38. f Trajectories of dead larvae in stage 38

larvae that (while still passing in greater numbers near the bed) follow a more linear trajectory past the cylinder.

For submerged vegetation (trial 3), velocity was damped within the array (Fig. 5a) due to the drag force exerted by the vegetation. Velocity decays from $0.18 \mathrm{~m} \mathrm{~s}^{-1}$ at the free surface to less than $0.05 \mathrm{~m} \mathrm{~s}^{-1}$ deep within the array. This transition, while not as sharp as the transition observed in trial 1 (gravel bump), generates a shear layer which produces similar turbulent kinetic energy and vorticity patterns as trial 1, though with lower magnitudes $\left(k_{\max }=0.2 \mathrm{~m}^{2} \mathrm{~s}^{-2}\right.$ and $\omega_{\max }=-1.5 \times 10^{-3} \mathrm{~s}^{-1}$ ) than in the gravel bump. Regions of low $k$ (above and below the top of the array) show a clear shear layer with maximum $k$ and $\omega$ at the top of the array (Fig. 5b, c). 


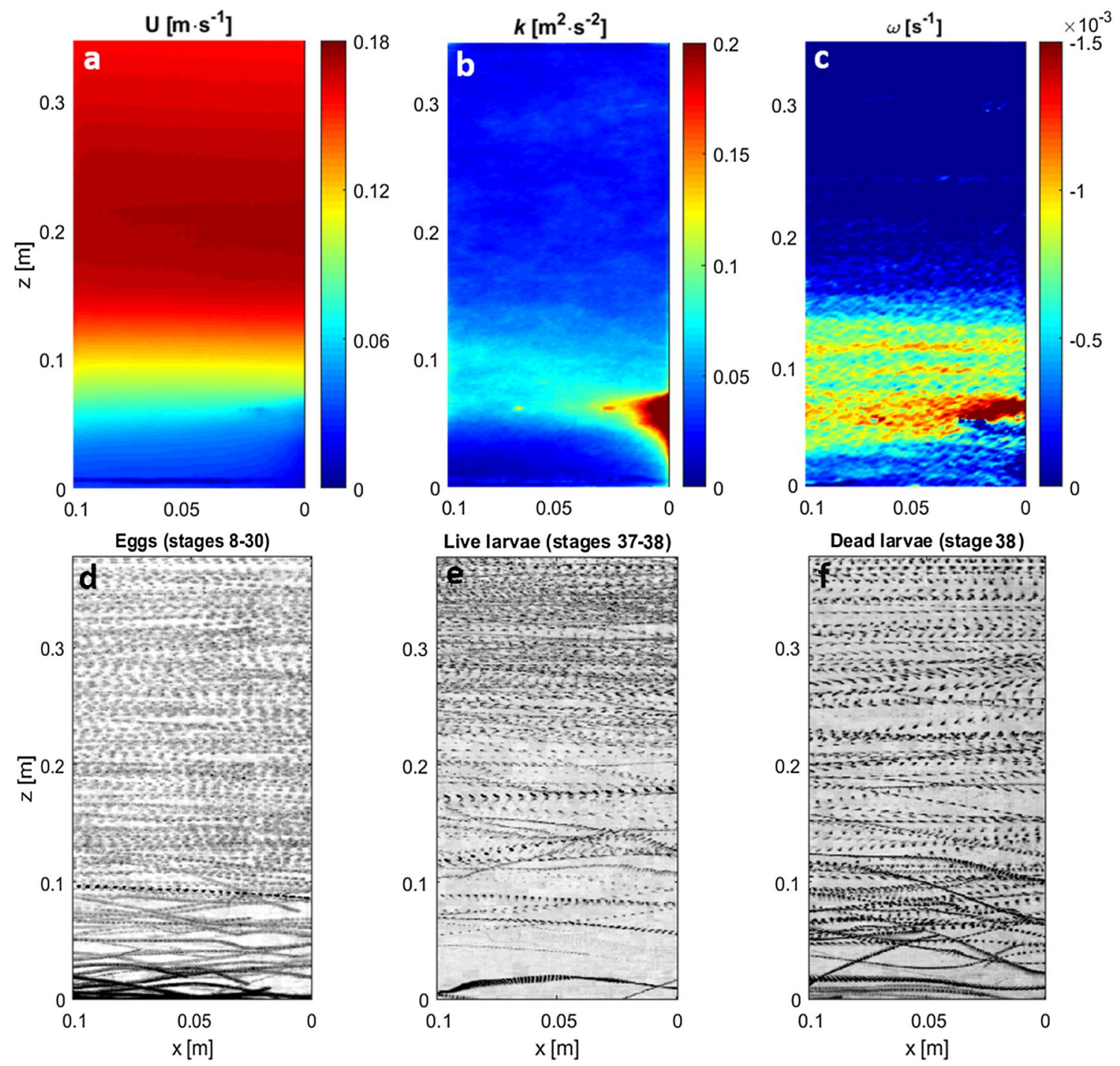

Fig. 5 Maps of flow conditions and trajectories of eggs and larvae under the presence of the submerged vegetation along the straight section. a Map of streamwise flow velocity. b Map of turbulent

Drifting and swimming patterns for trial 3 vary amongst "inert particles" and live larvae. Eggs (Fig. 5d) are found almost uniformly within the water column, with slightly less accumulation deep within the array. Live larvae (Fig. 5e) accumulated near the free surface, as far as possible away from the array-generated shear, clearly avoiding regions of high shear and high $k$, while dead larvae (Fig. 5f) are similar in distribution to eggs, evenly distributed across the water column.

\section{Survival rates}

We compared survival rates for all trials against control test on hatching jars (as explained in Prada et al. 2018). There was a mortality of at least $55 \%$ in hatching jars, which can kinetic energy. c Map of vorticity. d Trajectories of eggs. e Trajectories of live larvae in stage 38 . $\mathbf{f}$ Trajectories of dead larvae in stage 38

be attributed to biological causes since eggs and larvae were maintained under standard aquaculture conditions of oxygenation and temperature. Results of survival rates in both RTF and hatching jars can be found in Table 1.

The poor quality of eggs in trial 3 due to atresia in the female injected for spawning highly affected the survival rates in this trial in both jars and RTF. Survival rates of only $5.5 \%$ and $3.4 \%$ respectively ( $-38.2 \%$ difference) were obtained in this trial, which subsequently affected the analysis of transient distributions of eggs and larvae across the water column. For the other two trials, survival rates were much higher than in trial 3 , and also showed us that mortality was higher in the RTF, due to the eggs and larvae traveling through moving water, interacting with sediment and obstructions, and experiencing higher levels of 
Table 1 Survival rates in RTF and hatching jars after experiment

\begin{tabular}{llllll}
\hline Case & $\begin{array}{l}\text { Eggs } \\
\text { stocked to } \\
\text { jars }\end{array}$ & $\begin{array}{l}\text { Survival } \\
\text { rate in } \\
\text { jars }\end{array}$ & $\begin{array}{l}\text { Eggs } \\
\text { stocked to } \\
\text { flume }\end{array}$ & $\begin{array}{l}\text { Survival } \\
\text { rate in } \\
\text { flume }\end{array}$ & $\begin{array}{l}\text { Difference in survival } \\
\text { rates between flume and } \\
\text { jars }\end{array}$ \\
\hline Trial 1: Gravel bump & 2000 & $35.9 \%$ & 4000 & $33.5 \%$ & $-6.7 \%$ \\
Trial 2: Single cylinder & 2000 & $44.9 \%$ & 4000 & $39.6 \%$ & $-11.8 \%$ \\
Trial 3: Submerged vegetation & 400 & $5.5 \%$ & 4000 & $3.4 \%$ & $-38.2 \%$ \\
\hline
\end{tabular}
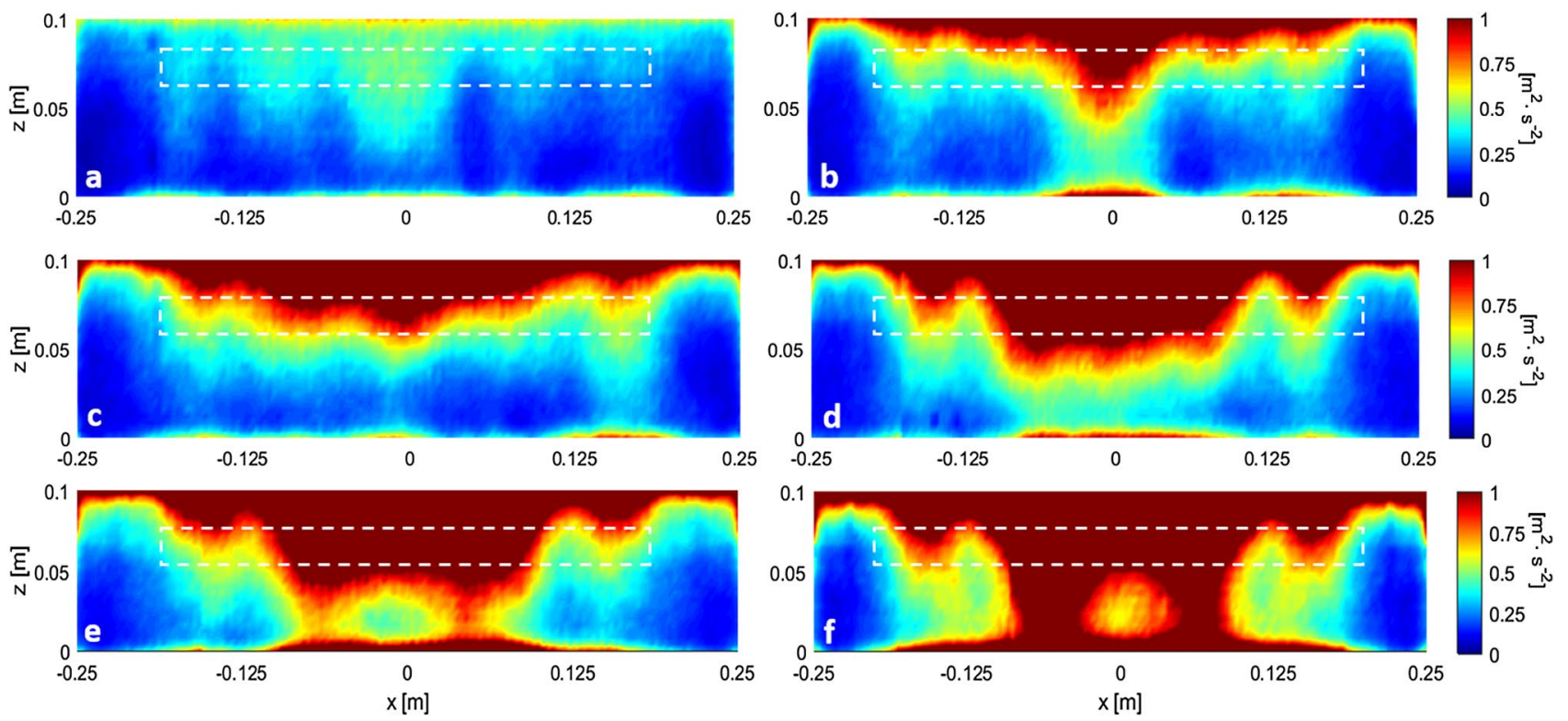

Fig. 6 Turbulent kinetic energy $(k)$ distributions in the turbulence tank with dashed zones considered to estimate maximum $k$. a $f=100 \mathrm{~Hz}$. b $f=200 \mathrm{~Hz}$. c $f=240 \mathrm{~Hz}$. d $f=320 \mathrm{~Hz}$. e $f=360 \mathrm{~Hz}$. $f=400 \mathrm{~Hz}$

turbulence both at the obstructions and at the disk pump $(-6.7 \%$ and $-11.8 \%$ difference in survival rates for trials 1 and 2 respectively).

In trial 1 , some of the eggs in suspension were in contact with the gravel bump or settled for some time at the zone of low velocity and low turbulence downstream of this obstruction. However, they were not buried in the sediment; eggs were continuously picked up by passing eddies, thus the overall survival was not directly affected by the recirculation zone.

For the turbulence tank tests, eggs were in suspension for all oscillation frequencies due to the turbulence below the grid within a $0.1-\mathrm{m}$ gap between the grid and the bottom wall as they were lifted by the turbulence fluctuations. Turbulent kinetic energy fields obtained from PIV measurements in this gap are shown in Fig. 6. Time-averaged values of up to $k=1.0 \mathrm{~m}^{2} \mathrm{~s}^{-2}$ and maximum magnitude of $k_{\max }=2.70 \mathrm{~m}^{2} \mathrm{~s}^{-2}$ were registered slightly above middepth (highlighted in Fig. 6) for the highest frequency of the stirred grid $(f=400 \mathrm{~Hz})$. The maximum $k\left(k_{\max }\right)$ measured in each case was plotted against the survival rates (Fig. 7). Survival rates were very similar (near 90\%) for the slower

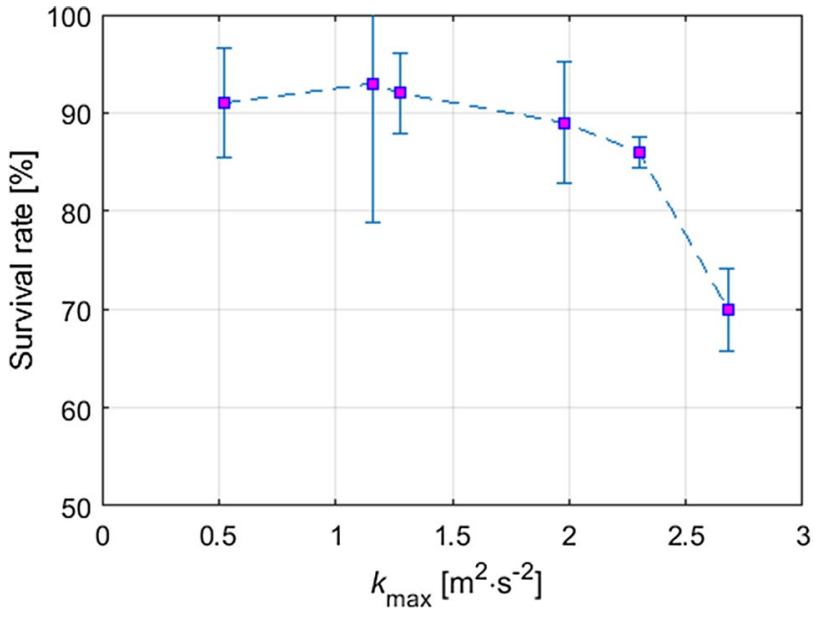

Fig. 7 Mortality of water-hardened eggs exposed to turbulence generated within the grid-stirred turbulence tank for a 1-min exposure

cases where $k_{\max }$ did not exceed $2.0 \mathrm{~m}^{2} \mathrm{~s}^{-2}$, suggesting that within this range the damage to a few eggs in each batch was most likely due to handling. A drop in survival rates occurs 
when $k_{\max }$ is greater than $2.0 \mathrm{~m}^{2} \mathrm{~s}^{-2}$. At $k_{\max }\left(=2.7 \mathrm{~m}^{2} \mathrm{~s}^{-2}\right)$, survival rates were reduced to around $70 \%$. For reference, $k_{\max }$ in a stilling basin downstream of a dam spillway can reach $10 \mathrm{~m}^{2} \mathrm{~s}^{-2}$ and maintain values above $2 \mathrm{~m}^{2} \mathrm{~s}^{-2}$ for up to $100 \mathrm{~m}$ downstream of the spillway (Zhao and Wang 2019).

Reynolds stresses $\left(\tau_{x z}\right)$, which have units of force per unit area $\left(\mathrm{N} \mathrm{m}^{-2}\right)$, were also estimated from PIV measurements applying Eq. 2 (Fig. 8). Reynolds stresses in the turbulence tank reached values greater than $30 \mathrm{~N} \mathrm{~m}^{-2}$ in some regions near the grid, values comparable to bed stresses recorded in medium-sized streams, $\sim 30 \mathrm{~N} \mathrm{~m}^{-2}$ (Statzner and Müller 1989).

\section{Eggs and larvae spatial distributions}

A wide range in egg size was obtained amongst all trials (3-5 mm), which is a representative sample of the common range of grass carp eggs in natural settings (KorwinKossakowski 2008). Nearly translucent eggs were visible in the images due to the opacity of the yolk. Once they hatched, approximately $30 \mathrm{~h}$ after fertilization, larvae were almost transparent. Although difficult to see without proper illumination, larvae were identifiable against the lit background. At approximately $65 \mathrm{~h}$ post fertilization, pigmentation in the eyes and back of the larvae increased, allowing for easier detection. A total of 4985 time-lapse photos was taken on trial 1, 5063 on trial 2, and 1920 on trial 3, all at 1-minute intervals. These pictures allow us to extract vertical distributions of particles detected through the $\sim 85$ consecutive hours of analysis (represented as colormaps in Fig. 9), along with the total number of particles detected at each time step (time series on top of each colormap on Fig. 9).
For trial 1 (Fig. 9a), in period 1 (developmental stages $8-30$ ), eggs were detected mostly in the lower $50 \%$ of the water column, with about $40 \%$ of them just downstream of the gravel bump. In the vertical-swimming period 2 (preGBI, developmental stages 31-36), larvae were more evenly spread throughout the water column. In period 3 (post-GBI, developmental stages 37-38), larvae swam horizontally and remained suspended near the bottom, also downstream of the gravel bump, but more concentrated with about $60 \%$ of them in this low-velocity area. Larvae in period 3 showed a clear tendency to swim towards zones of low turbulence and vorticity levels (Fig. 3b, c), and used the gravel bump as a shelter, with active swimming within that low turbulence and shear zone.

For trial 2 (Fig. 9b), the vertical distribution of eggs and larvae was fairly consistent throughout the experiment. Eggs and larvae were spread across the water depth although more concentrated towards the bottom, especially for larvae in period $3(\sim 30 \%)$. For trial 3 (Fig. 9c), in period 1, eggs spread almost uniformly across the water column, with a slightly larger number concentrated near the bottom. In period 2 of trial 3, because the survival rate was very low in the RTF (3.4\%, only 136 larvae recovered out of 4,000 eggs), the experiment was stopped $2 \mathrm{~h}$ after the end of period 1 . At the end of trial 2, we predicted possible spawning issues could occur for our last trial (trial 3, submerged vegetation) due to atresia in the available females, which would result in low quality eggs and low survival rate. To ensure enough larvae to test our submerged vegetation scenario (trial 3), the surviving larvae from trial 2 (in stage 38) were used for testing the conditions of trial 3 . As expected, the batch of eggs used for trial 3 allowed us to test the egg stage, but lack
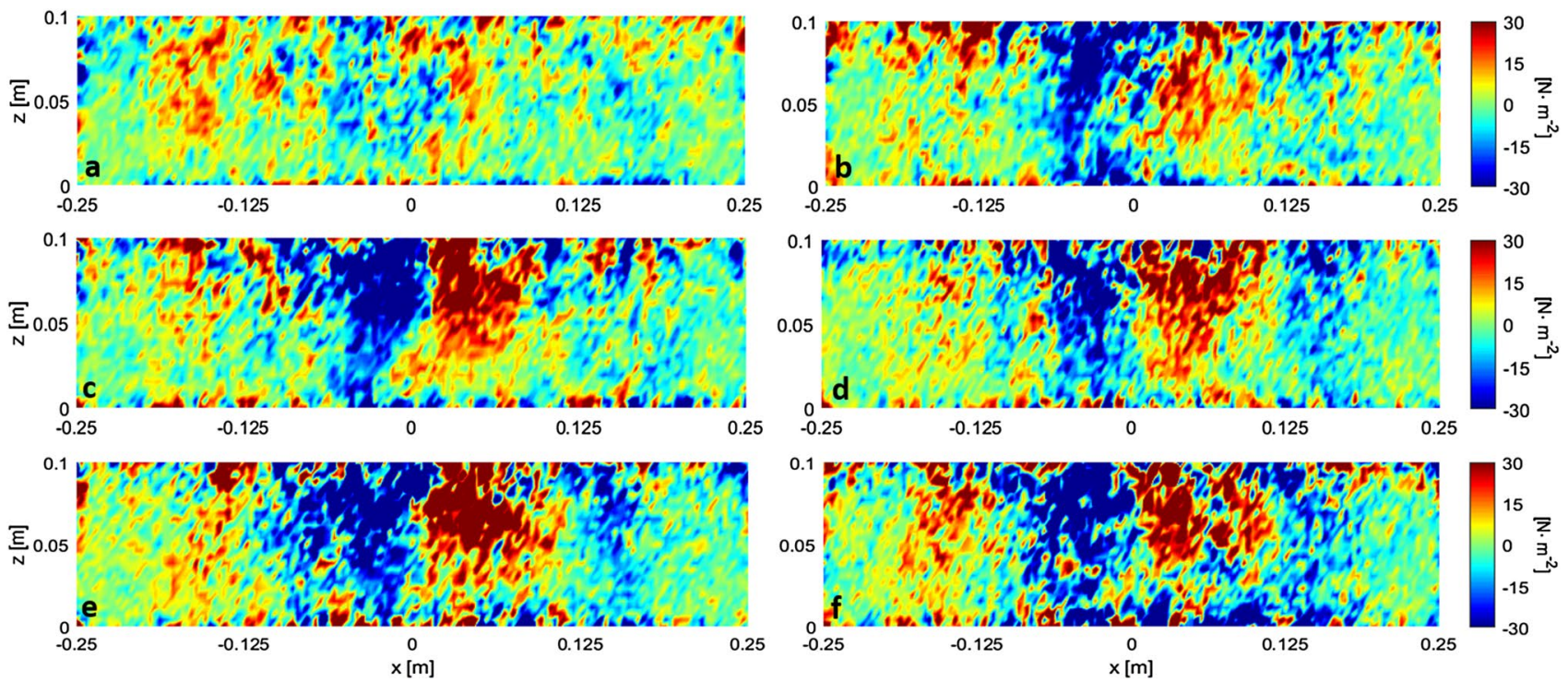

Fig. 8 Distribution of Reynolds stresses in the turbulence tank. a $f=100 \mathrm{~Hz} . \mathbf{b} f=200 \mathrm{~Hz} . \mathbf{c} f=240 \mathrm{~Hz}$. d $f=320 \mathrm{~Hz} . \mathbf{e} f=360 \mathrm{~Hz}$. f $f=400 \mathrm{~Hz}$ 

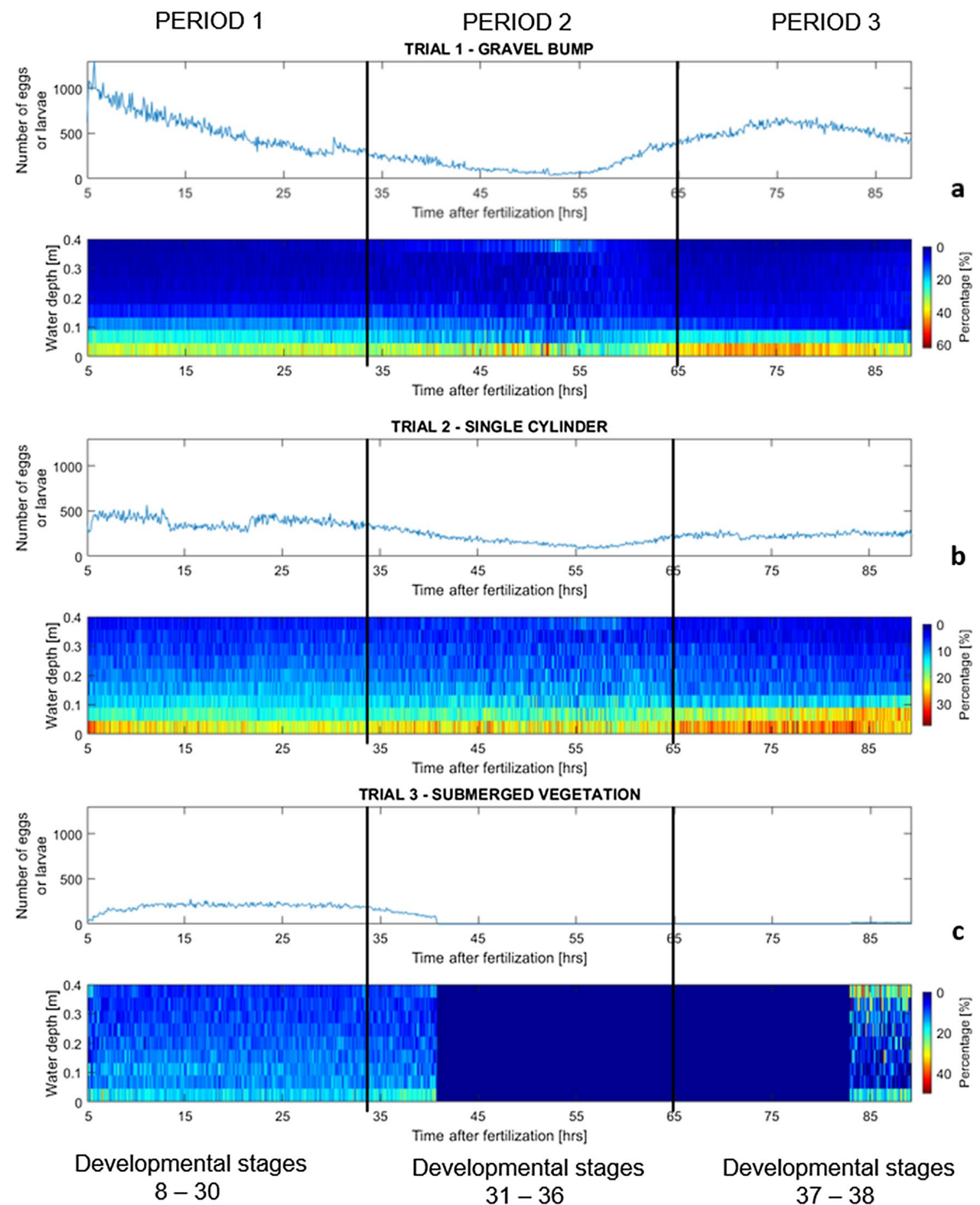

Developmental stages

$31-36$

Developmental stages
$37-38$

Fig. 9 Number of particles identified along the length of the experiments and vertical distribution of egg and larvae across the water depth. a Trial 1 (gravel bump), b trial 2 (single cylinder), $\mathbf{c}$ trial 3 (submerged vegetation)

of successful hatching prevented us from using that batch for the larvae trials.

Figure 10 shows the 2D plots of percentage distributions. Distances ( $x$ and $y$ ) in Fig. 10 were scaled using the water depth $(h)$, and the obstructions, gravel bump and single cylinder, are just beyond the window of analysis, with the right border of the window corresponding to the downstream edge of the bump and the cylinder. In trial 1 (gravel bump), the majority of eggs and pre-GBI larvae were found within a distance no longer than about $0.20 h$ from the downstream edge of the bump down in the region of low $k$. However, larvae in stages $37-38$ were more likely to be found towards $0.3-0.6 h$ 

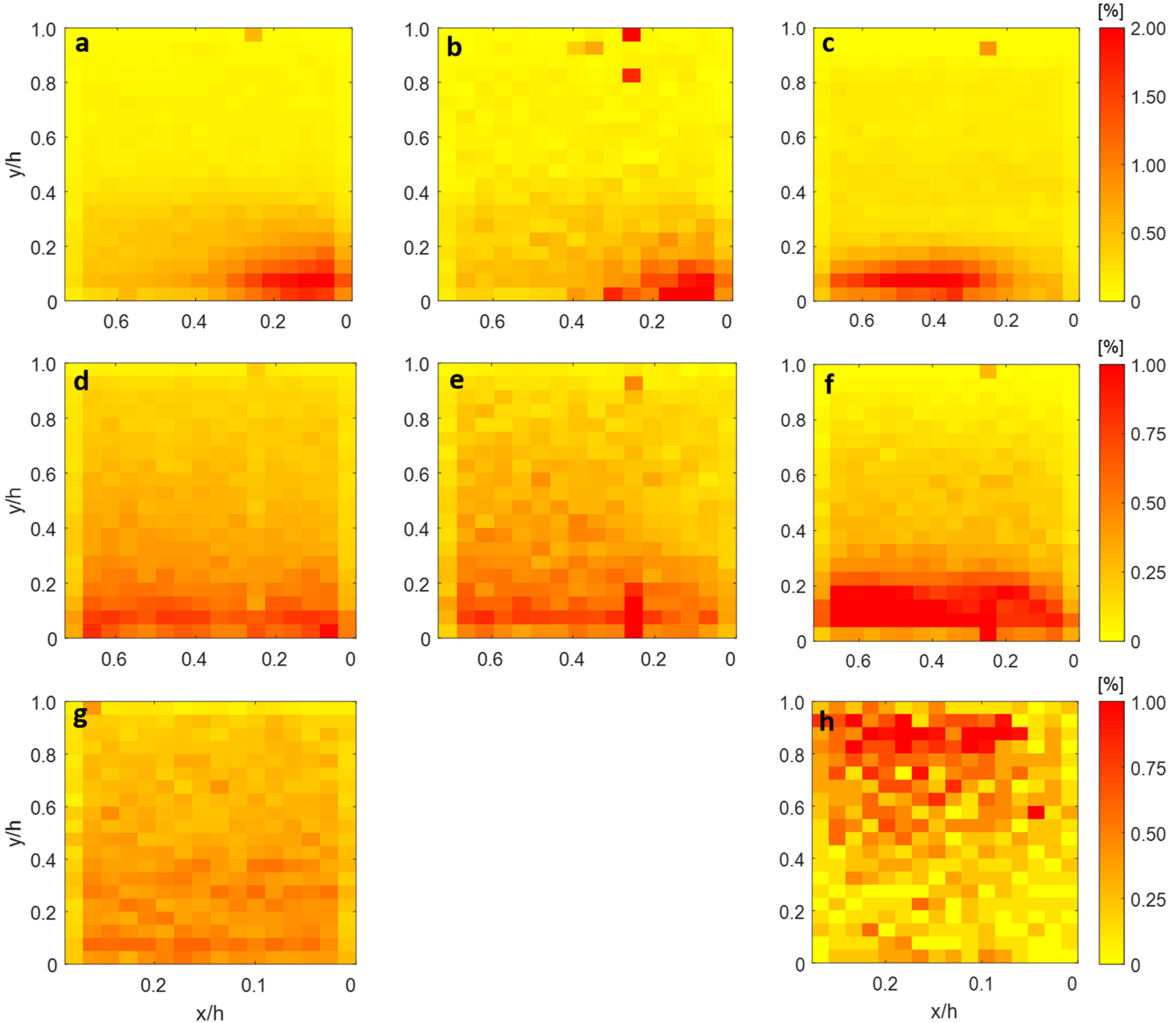

Fig. 10 Distributions of eggs and larvae downstream of each obstruction presented as a percentage. $x-y$ axes were non-dimensionalized with the water depth $(h)$. a-c Trial 1: eggs, pre-GBI larvae, and

post-GBI larvae respectively. $\mathbf{d}-\mathbf{f}$ Trial 2: eggs, pre-GBI larvae, and post-GBI larvae respectively. $\mathbf{g}-\mathbf{h}$ Trial 3: eggs, and post-GBI larvae respectively. Note that the colorbar for $(\mathbf{a}-\mathbf{c})$ has a different scale

downstream of the bump. In the other two cases, the single cylinder and submerged vegetation, eggs and larvae in both stages were more uniformly distributed within the window of analysis at the water depths observed in Fig. 9.

\section{Discussion}

In our characterization of the interaction between grass carp eggs and larvae with in-stream obstructions, we identified typical distributions of eggs and larvae throughout the water column in relation to turbulence and vorticity levels, and related turbulence to the rates of mortality of

eggs in moving water. Survival of early life stages of fish is highly variable and mortality can result from any number of causes (Houde 2002), but the physical factors in this experiment can be important when considering natural mortality rates. In a previous experiment, Prada et al. (2018) reported an increase in mortality due to a combination of higher levels of velocity, turbulence, and abrasion by interaction with sediment particles on a flat bed. In this study, we also observed higher mortality rates due to interaction of eggs and larvae with sediment bed, instream obstructions, and high turbulence levels compared to the control jars. However, the in-stream obstructions did not substantially increase the egg mortality compared to 
Prada et al. (2018) where higher flow speeds caused: (a) higher resuspension rates resulting in more egg-sediment interaction and abrasion, (b) higher shear experienced by eggs and larvae as they passed through the disk pump, and (c) direct impact with the disks at the highest speed. This is part of the motivation behind the turbulence tank study, to isolate the effect of pure shear and turbulence from sediment- and disk-interactions.

We tested the effect of pure turbulence in a grid-stirred turbulence tank noticing an increase in mortality for magnitudes of $k$ greater than $2.0 \mathrm{~m}^{2} \mathrm{~s}^{-2}$, and stresses $\tau_{x z}$ greater than $20 \mathrm{~N} \mathrm{~m}^{-2}$ for exposures of $1 \mathrm{~min}$; time sufficient to increase mortality rates by nearly $30 \%$ once $k$ reached $2.7 \mathrm{~m}^{2} \mathrm{~s}^{-2}$ (or $\tau_{x z}>30 \mathrm{~N} \mathrm{~m}^{-2}$ ). Such thresholds of $k$ and $\tau_{x z}$ can be applied to identify field conditions with the potential to reduce successful hatching of eggs in natural streams, and evaluate whether natural or anthropogenic features could cause mortality where survival of eggs is desirable. For example, turbulent kinetic energy can be high below dams where $k$ can exceed $2.0 \mathrm{~m}^{2} \mathrm{~s}^{-2}$ throughout the water column and persist for relatively large distances downstream of the structure (100 m) (Zhou and Wang 2019). Odeh et al. (2002) listed previous reports that documented magnitudes of common shear stresses (in $\mathrm{N} \mathrm{m}^{-2}$ ) associated with average flows in natural streams (see Table 2). Lancaster and Hildrew (1993) measured near-bed shear stresses in small streams ( $W=1.38$ to $3.15 \mathrm{~m}, D=0.123$ to $0.245 \mathrm{~m}$ ) of $1 \mathrm{~N} \mathrm{~m}^{-2}$ at moderate discharges $\left(\sim 0.006 \mathrm{~m}^{3} \mathrm{~s}^{-1}\right)$ and less than $7 \mathrm{~N} \mathrm{~m}^{-2}$ at high discharges $\left(\sim 0.543 \mathrm{~m}^{3} \mathrm{~s}^{-1}\right)$, and Statzner and Müller (1989) reported 90 measurements of near-bed shear stress in 3 medium-sized streams ( $W=2$ to $6 \mathrm{~m}, Q_{\text {base }}=0.4$ to $1.42 \mathrm{~m}^{3} \mathrm{~s}^{-1}$ ) with most estimates near $30 \mathrm{~N} \mathrm{~m}^{-2}$, where $W$ is mean channel width, $D$ is mean channel depth, and $Q_{\text {base }}$ is baseflow discharge. Large rivers, such as the Mississippi River, produce shear stresses of 6 to $10 \mathrm{~N} \mathrm{~m}^{-2}$ in flood stage (Costa 1987), though local shear stresses can be highly variable especially near in-stream structures (Jamieson et al. 2011). Such data can be used to compare against experimental thresholds to identify areas in streams where most damage to the eggs is expected.
Our vertical distributions in 1D and 2D (Figs. 8 and 9) provide insight into changes in behavior as the larvae hatch and develop their swimming capabilities. Consistent with George et al. (2018), larvae at GBI stages (37-38) showed strong active swimming capabilities including high maximum speeds that allowed them to search for and remain in areas of low shear and turbulence. As observed in Prada et al. (2018), larvae seldom exceeded the velocity of the water to travel upstream when in the main flow field, but did use short burst movements to escape zones of higher turbulence and shear. In areas with low turbulence and shear (e.g. behind the gravel bump), movement occurred in all directions and at a range of velocities. Swimming abilities and speeds further increase with ontogeny, and more advanced larvae would be expected to be able to effectively use different areas of flow refuge when moving laterally from the mainstream river into nursery habitats. These capabilities were corroborated by contrasting the flow fields with trajectories and spatial distributions of both live and dead larvae. The trajectories followed by dead larvae were merely driven by the flow, instantaneous turbulent fluctuations, and coherent flow structures capturing larvae as inert particles suspended in flow, showing a behavior similar to eggs.

Comparing the flow fields in trials 1 and 3, we found some similarities in velocity profiles. Both are reduced towards $0 \mathrm{~m} \mathrm{~s}^{-1}$ as flow interacts with the obstruction. However, there are two fundamental differences between these cases: (1) There is a clear recirculation zone behind the gravel bump, driven by large eddies on a vertical $x-z$ plane, which propagates far downstream from the obstacle in trial 1 ; but no recirculation area within the gap in the array of rigid cylinders. (2) The gravel in trial 1 generated coherent flow structures mostly on the $x-z$ plane, whereas the rigid cylinder array generated smaller stem-scale eddies on $x-y$ planes. Thus, even if the flow speed was reduced within the array, larvae did not actively seek this region for shelter; they instead avoided this region.

Turbulent eddies created by the vegetation array scale with the diameter of individual cylinders $(6.4 \mathrm{~mm})$, which is close to the size of larvae $(\sim 10 \mathrm{~mm})$. These results are
Table 2 Estimates of shear stress in natural and altered aquatic systems ( adopted from Odeh et al 2002)

\begin{tabular}{lll}
\hline Environment & Shear stress $\left(\mathrm{N} \mathrm{m}^{-2}\right)$ & Reference \\
\hline $\begin{array}{l}\text { Water column in a trout stream, } \\
\text { average flow }\end{array}$ & $<1.0$ & Fausch and White (1981) \\
Small streams, near bed & $<1.0-7.0$ & \\
Medium-sized streams, near bed & Most $<30$, although some $>200$ & Lancaster and Hildrew (1993) \\
Flash floods, small basins & $61-2600$ & Costa (1987) \\
Floods, large rivers & $6-10$ & Costa (1987) \\
Bulb turbine draft tube & $500-5,421$ & McEwen and Scobie (1992) \\
Near ships' hulls and wakes & $7.6-40.4$ & Morgan et al (1976) \\
Near barge propeller & $\geq 5,000$ & Killgore et al (1987) \\
\hline
\end{tabular}


specific for arrays of rigid cylinders, where a single relevant scale (i.e. stem diameter) drives the stem-scale turbulence generation. Flexible vegetation in the field could provide shelter for larvae due to the multiple length scales present in patches of flexible aquatic vegetation. A denser and more heterogeneous patch would allow for recirculation zones within the patch, more like the scenario in trial 1. However, our study with rigid cylinders allowed us to identify turbulence scales that were not attractive for grass carp larvae.

Although swimming biomechanics vary among species, fish larvae in general adopt a resistive swimming style, propelling themselves with undulations of their body, thus generating wakes and flows (Müller et al. 2000, 2007). The presence of coherent flow structures can further affect fish response to these flows, particularly if the size of the eddies is similar to the size of the larvae (Pavlov et al. 2000; Cada and Odeh 2001; Smith et al. 2014). Each eddy has the energy and momentum to transfer rotation over a submerged body of similar size. Eddies of the same size as the larvae are able to destabilize their position relative to the flow, affecting their swimming capabilities (Pavlov et al. 2008). As noticed in the case of submerged vegetation, where the size of stem-scale eddies was within the same order of magnitude as the size of larvae, eddies can drive larvae away from the array. Larvae prefer to swim above the array where velocity is higher but $k$ and $\omega$ are smaller. Our data suggest the possibility to design a similar flow scenario in rivers that would allow a directed movement of larvae into particular areas to reduce or enhance recruitment, as desired, based not only on magnitude of turbulence, but also on its representative length scales. In the case of invasive species, movement could be directed to poor habitat quality that would reduce recruitment, or areas where larvae could be easily collected.

Rehmann et al. (2003) and Kozarek et al. (2018) noted that mortality of zebra mussel veligers is a function of size, exposure time, and turbulent energy dissipation. We found that acute exposure to high turbulence during short periods of time ( 1 min) can increase mortality in grass carp eggs. Whether longer exposures to lower levels of shear and turbulence would cause similar effects will be investigated in an ongoing project. The marked increase in mortality at higher turbulence found in the turbulence tank provides partial explanation for increased mortality in the RTF as the values of high $k$ estimated for trials 1 and 2 (i.e. bump and cylinder) were on the same order of magnitude as $k_{\max }$ for the higher frequencies in the turbulence tank. In-stream structures and control mechanisms, such as the simplified geometries tested in these trials, weirs, or bubble curtains, could be designed to force grass carp eggs to pass through or be detained in high turbulence zones, potentially increasing mortality rates in streams during spawning seasons. Early life stages of the bigheaded carps are largely similar to the grass carp, and these results are likely applicable to control or enhancement of those species as well. Furthermore, most North American fishes with drifting eggs and larvae spawn earlier in the year than grass carp or bigheaded carps (Galat et al. 2005), thus such control mechanisms might be deployed only at times which would minimize effects on native fish but maximize effects on invasive carps.

By quantifying the altered flow due to in-stream obstructions (velocity, turbulence, and vorticity fields), and relating them to changes in mortality, as well as identifying pathways and swimming capabilities of grass carp eggs and larvae, we have generated a unique dataset to better inform monitoring, sampling, and control of grass carp recruitment in streams. Our observations serve as the basis for improvements of field campaigns for sampling and collection of early life stage fish, as well as for the development of new strategies to control the spread of this species where it is invasive, or to enhance survival where it is desirable. The susceptibility to turbulence at embryonic stages reported in this study may be considered a key factor in the design of alternatives that promote or reduce the trapping of eggs at high turbulence, thus affecting the probability of successful hatching in natural streams. While lower survival rates attributed to high turbulence levels may help decrease invasion risk, turbulence alone may not be enough to ensure protection to vulnerable waterbodies. Further studies should explore the effect on mortality at even earlier life stages, i.e., pre-water hardened eggs, when the eggs might be more susceptible to damage.

Acknowledgements Research was funded by the Cooperative Agreement G18AS00001 for CESU-affiliated Partner with U.S. Geological Survey- Great Rivers Cooperative Ecosystem Studies Unit. We thank C. Byrd, S. Erwin, and two anonymous reviewers for their comments as part of the peer-review of the manuscript. We thank the facilities staff of the University of Illinois, and C-Y Tseng for his assistance with PIV measurements. Any use of trade, firm, or product names is for descriptive purposes only and does not imply endorsement by the U.S. Government. Data presented herein is available at https://doi. org/10.5066/P926SZLN.

Open Access This article is licensed under a Creative Commons Attribution 4.0 International License, which permits use, sharing, adaptation, distribution and reproduction in any medium or format, as long as you give appropriate credit to the original author(s) and the source, provide a link to the Creative Commons licence, and indicate if changes were made. The images or other third party material in this article are included in the article's Creative Commons licence, unless indicated otherwise in a credit line to the material. If material is not included in the article's Creative Commons licence and your intended use is not permitted by statutory regulation or exceeds the permitted use, you will need to obtain permission directly from the copyright holder. To view a copy of this licence, visit http://creativecommons.org/licenses/by/4.0/. 


\section{References}

Cada GF, Odeh M (2001) Turbulence at hydroelectric power plants and its potential effects on fish. BPA Report DOE/BP-26531-1. https://digital.library.unt.edu/ark:/67531/metadc715813/m2/1/ high_res_d/781814.pdf. Accessed 3 Feb 2019.

Chapman DC (2006) Early development of four cyprinids native to the Yangtze River, China. U.S. Geological Survey, Data Series 239. https://pubs.usgs.gov/ds/2006/239/pdf/ds2006-239.pdf. Accessed 24 Sep 2018.

Chapman DC, Chen D, Hoover JJ, Du H, Phelps QE, Shen L, Wang C, Wei Q, Zhang H (2016) Bigheaded carps of the Yangtze and Mississippi rivers: biology, status, and management. In: Chen Y, Chapman DC, Jackson JR, Chen D, Li Z, Killgore KJ, Phelps Q, Eggleston MA (eds) Fishery resources, environment, and conservation in the Mississippi and Yangtze (Changjiang) river basins. American Fisheries Society, Bethesda, pp 113-126

Chick JH, Pegg MA (2001) Invasive carp in the Mississippi River Basin. Science 292(5525):2250-2251. https://doi.org/10.1126/ science.292.5525.2250

Chilton EW, Muoneke MI (1992) Biology and management of grass carp (Ctenopharyngodon idella, Cyprinidae) for vegetation control: a North American perspective. Rev Fish Biol Fisher 2(4):283-320. https://doi.org/10.1007/BF00043520

Conover G, Simmonds R, Whalen M (2007) Management and control plan for bighead, black, grass, and silver carp in the United States. Asian Carp Working Group, Aquatic Nuisance Species Task Force, Washington, DC. https://www.anstaskforce.gov/ Documents/Carps_Management_Plan.pdf. Accessed 18 Oct 2018.

Costa JE (1987) Hydraulics and basin morphometry of the largest flash floods in the conterminous United States. J Hydrol 93:313-338. https://doi.org/10.1016/0022-1694(87)90102-8

Coulter AA, Bailey EJ, Keller D, Goforth RR (2016) Invasive silver carp movement patterns in the predominantly free-flowing Wabash River (Indiana, USA). Biol Invasions 18(2):471-485. https://doi.org/10.1007/s10530-015-1020-2

Cudmore B, Mandrak NE, Dettmers JM, Chapman DC, Kolar, CS (2012) Binational ecological risk assessment of bigheaded carps (Hypophthalmichthys spp.) for the Great Lakes Basin (No. 2011/114). DFO, Ottawa. https://waves-vagues.dfo-mpo.gc.ca/ Library/346685.pdf. Accessed 30 Nov 2018.

Embke HS, Kocovsky PM, Richter CA, Pritt JJ, Mayer CM, Qian SS (2016) First direct confirmation of grass carp spawning in a Great Lakes tributary. J Great Lakes Res 42(4):899-903. https ://doi.org/10.1016/j.jglr.2016.05.002

Embke HS, Kocovsky PM, Garcia T, Mayer CM, Qian SS (2019) Modeling framework to estimate spawning and hatching locations of pelagically spawned eggs. Can J Fish Aquat Sci 76(4):597-607. https://doi.org/10.1139/cjfas-2018-0047

Fausch KD, White RJ (1981) Competition between brook trout (Salvelinus fontinalis) and brown trout (Salmo trutta) positions in a Michigan stream. Can J Fish Aquat Sci 38(10):1220-1227. https://doi.org/10.1139/f81-164

Fedorenko AY, Fraiser FJ (1978) Review of grass carp biology. Fisheries and Marine Service, Tech. Rep. No. 786. https://www. dfo-mpo.gc.ca/Library/52357.pdf. Accessed 8 Feb 2019.

Galat DL, Berry CR, Gardner WM, Hendrickson JC, Mestl GE, Power G, Stone C, Winston MR (2005) Spatiotemporal patterns and changes in Missouri River fishes. American Fisheries Society Symposium 45:249-91. https://pdfs.semanticscholar .org/56f2/1664e7a2ace39bc6cba3c9f16806fedd8439.pdf

Garcia T, Jackson PR, Murphy EA, Valocchi AJ, Garcia MH (2013) Development of a fluvial egg drift simulator to evaluate the transport and dispersion of Asian carp eggs in rivers.
Ecol Model 263:211-222. https://doi.org/10.1016/j.ecolm odel.2013.05.005

Garcia T, Murphy EA, Jackson PR, Garcia MH (2015) Application of the FluEgg model to predict transport of Asian carp eggs in the Saint Joseph River (Great Lakes tributary). J Great Lakes Res 41(2):374-386. https://doi.org/10.1016/j.jglr.2015.02.003

George AE, Chapman DC (2015) Embryonic and larval development and early behavior in grass carp, Ctenopharyngodon idella: implications for recruitment in rivers. PLoS ONE 10(3):e0119023. https://doi.org/10.1371/journal.pone.0119023

George AE, Chapman DC, Deters JE, Erwin SO, Hayer CA (2015) Effects of sediment burial on grass carp, Ctenopharyngodon idella (Valenciennes, 1844), eggs. J Appl Ichthyol 31(6):1120-1126. https://doi.org/10.1111/jai.12918

George AE, Garcia T, Stahlschmidt BH, Chapman DC (2018) Ontogenetic changes in swimming speed of silver carp, bighead carp, and grass carp larvae: implications for larval dispersal. PeerJ 6:e5869. https://doi.org/10.7717/peerj.5869

Houde ED (2002) Mortality. In: Fuiman LA, Werner RG (eds) Fishery science. The unique contributions of early life stages. Blackwell, UK, pp 64-87

Jamieson EC, Rennie CD, Jacobson RB, Townsend RD (2011) 3-D flow and scour near a submerged wing dike: ADCP measurements on the Missouri River. Water Resour Res 47:W07544. https://doi. org/10.1029/2010WR010043

Jennings DP (1988) Bighead carp (Hypophthalmichthys nobilis) a biological synopsis. U.S. Fish and Wildlife Service, Biol Rep 88(29). https://apps.dtic.mil/dtic/tr/fulltext/u2/a322554.pdf. Accessed 15 Jul 2018.

Killgore KJ, Miller AC, Conley KC (1987) Effects of turbulence on yolk-sac larvae of paddlefish. Trans Am Fish Soc 116(4):670-673. https://doi.org/10.1577/1548-8659(1987)116<3c670:EOTOY $\mathrm{L}>2.0 . \mathrm{CO} ; 2$

Kočovský PM, Chapman DC, Qian SS (2018) "Asian carp" is socially and scientifically problematic. Let's replace it. Fisheries 43(7):311-316. https://doi.org/10.1002/fsh. 10087

Korwin-Kossakowski M (2008) The influence of temperature during the embryonic period on larval growth and development in carp, Cyprinus carpio L., and grass carp, Ctenopharyngodon idella (Val.): theoretical and practical aspects. Arch Pol Fish 16(3):231314. https://doi.org/10.2478/s10086-008-0020-6

Kozarek JL, Hondzo M, Kjelland ME, Piercy CD, Swannack TM (2018) Effects of turbulence exposure on zebra mussel (Dreissena polymorpha) larval survival. Aquat Sci 80:12. https://doi. org/10.1007/s00027-017-0563-y

Laird CA, Page LM (1996) Non-native fishes inhabiting the streams and lakes of Illinois. Illinois Natural History Survey Bulletin 35(1). https://www.archive.org/details/nonnativefishesi351lair. Accessed 20 Jan 2019.

Lancaster J, Hildrew AG (1993) Characterizing in-stream flow refugia. Can J Fish Aquat Sci 50(8):1663-1675. https://doi.org/10.1139/ f93-187

Lembi CA, Ritenour BG, Iverson EM, Forss EC (1978) The effects of vegetation removal by grass carp on water chemistry and phytoplankton in Indian ponds. Trans Am Fish Soc 107(1):161-171. https://doi.org/10.1577/1548-8659(1978)107<161:TEOVR $\mathrm{B}>2.0 . \mathrm{CO} ; 2$

Leslie AJ Jr, Nall LE, Van Dyke JM (1983) Effects of vegetation control by grass carp on selected water-quality variables in four Florida lakes. Trans Am Fish Soc 112(6):777-787. https://doi. org/10.1577/1548-8659(1983)112<777:EOVCBG > 2.0.CO;2

Liu M, Lin J, Peng Q, Yu L, Chen D, Liu S, Duan X (2018) Relationship between the distribution of broodstock and vorticity of spawning grounds of four major Chinese carps in the middle reaches of the Yangtze River during ecological operation of the 
Three Gorges Dam. Water 10(10):1487. https://doi.org/10.3390/ w10101487

McEwen D, Scobie G (1992) Estimation of the hydraulic conditions relating to fish passage through turbines. NPC001. National Engineering Laboratory, Glasgow.

Mitzner L (1978) Evaluation of biological control of nuisance aquatic vegetation by grass carp. Trans Am Fish Soc 107(1):135-145. https://doi.org/10.1577/1548-8659(1978)107<135:EOBCO $\mathrm{N}>2.0 . \mathrm{CO} ; 2$

Morgan RP, Ulanowicz RE, Rasin VJ, Noe LA, Gray GB (1976) Effects of shear on eggs and larvae of striped bass, Morone saxatilis, and white perch M. Americana. Trans Am Fish Soc 105(1):149 154. https://doi.org/10.1577/1548-8659(1976)105<149:EOSOE $\mathrm{A}>2.0 . \mathrm{CO} ; 2$

Müller UK, Stamhuis EJ, Videler JJ (2000) Hydrodynamics of unsteady fish swimming and the effects of body size: comparing the flow fields of fish larvae and adults. J Exp Biol 203(2):193-206. https ://jeb.biologists.org/content/203/2/193.

Müller UK, van den Boogaart JGM, van Leeuwen JL (2007) Flow patterns of larval fish: undulatory swimming in the intermediate flow regime. J Exp Biol 211(2):196-205. https://doi.org/10.1242/ jeb.005629

Odeh M, Noreika, JF, Haro A, Maynard A, Castro-Santos T, Cada GF (2002) Evaluation of the effects of turbulence on the behavior of migratory fish. U.S. Geological Survey, BPA Report DOE/ BP-00000022-1. https://tethys.pnnl.gov/sites/default/files/publi cations/Odeh-et-al-2002.pdf. Accessed 4 Aug 2018

Odell G, Kovasznay L (1971) A new type of water channel with density stratification. J Fluid Mech 50(3):535-543. https://doi. org/10.1017/S002211207100274X

Parker AD, Glover DC, Finney ST, Rogers PB, Stewart JG, Simmonds RL Jr (2016) Fish distribution, abundance, and behavioral interactions within a large electric dispersal barrier designed to prevent Asian carp movement. Can J Fish Aquat Sci 73:1060-1071. https ://doi.org/10.1139/cjfas-2015-0309

Pavlov DS, Lupandin AI, Skorobogatov MA (2000) The effects of flow turbulence on the behavior and distribution of fish. J Ichthy 40(2):232-261

Pavlov DS, Mikheev VN, Lupandin AI, Skorobogatov MA (2008) Ecological and behavioural influences on juvenile fish migrations in regulated rivers: a review of experimental and field studies. Hydrobiologia 609:125-138. https://doi.org/10.1007/s1075 0-008-9396-y

Piper RG, McElwain IB, Orme LE, McCraren JP, Fowler LG, Leonard JR (1982) Fish hatchery management. U.S. Fish and Wildlife Service, Washington, DC

Prada AF, George AE, Stahlschmidt BH, Chapman DC, Tinoco RO (2018) Survival and drifting patterns of grass carp eggs and larvae in response to interactions with flow and sediment in a laboratory flume. PLoS ONE 13(12):e0208326. https://doi.org/10.1371/journ al.pone. 0208326

Rehmann CR, Stoeckel JA, Schneider DW (2003) Effect of turbulence on the mortality of zebra mussel veligers. Can J Zool 81(6):10631069. https://doi.org/10.1139/z03-090

Schrank SJ, Guy CS (2002) Age, growth, and gonadal characteristics of adult big head carp, Hypophthalmichthys nobilis, in the lower Missouri River. Environ Biol Fishes 64(4):443-450. https://doi. org/10.1023/A:1016144529734

Shireman JV, Smith CR (1983) Synopsis of biological data on the grass carp, Ctenopharyngodon idella (Cuvier and Valenciennes, 1844). FAO Fisheries Synopsis No. 135. https://www.fao.org/3/a-ap938 e.pdf. Accessed 21 Nov 2018.

Smith DL, Goodwin RA, Nestler JM (2014) Relating turbulence and fish habitat: a new approach for management and research. Rev Fish Sci Aquac 22(2):123-130. https://doi.org/10.1080/10641 262.2013.803516

Soria J (1996) An investigation of the near wake of a circular cylinder using a video-based digital cross-correlation particle image velocimetry technique. Exp Therm Fluid Sci 12(2):221-233. https ://doi.org/10.1016/0894-1777(95)00086-0

Stainbrook KM, Dettmers JM, Trudeau TN (2007) Predicting suitable Asian carp habitat in the Illinois waterway using geographic information systems. INHS Tech. Rep. (07) https://hdl.handl e.net/2142/18155. Accessed 23 Jan 2019.

Statzner B, Müller R (1989) Standard hemispheres as indicators of flow characteristics in lotic benthos research. Freshwater Biol 21(3):445-459. https://doi.org/10.1111/j.1365-2427.1989.tb013 77. $\mathrm{x}$

Thielicke W, Stamhuis EJ (2014) PIVlab-towards user-friendly, affordable and accurate digital particle image velocimetry in MATLAB. J Open Res Softw 2(1):e30. https://doi.org/10.5334/ jors.bl

Yi B, Liang Z, Yu Z, Lin R, He M (1988) A comparative study on the early development of grass carp, black carp, silver carp, and big head of the Yangtze River. Gezhouba water control project and four famous fishes in the Yangtze River, China. Hubei Science and Technology Press, Wuhan, pp 69-135

Zhou Z, Wang J (2019) Numerical modeling of 3D flow field among a compound stilling basin. Math Probl Eng 2019:5934274. https:// doi.org/10.1155/2019/5934274

Publisher's Note Springer Nature remains neutral with regard to jurisdictional claims in published maps and institutional affiliations. 